Research Paper

\title{
Progression-free Survival Decreases with Each Subsequent Therapy in Pa- tients Presenting for Phase I Clinical Trials
}

\author{
Christopher H. Bailey¹, Gayle Jameson ${ }^{1}$, Chao Sima², Sharon Fleck1, Erica White ${ }^{1}$, Daniel D. Von Hoff1,2, \\ Glen J. Weiss ${ }^{1,2}{ }^{\square}$
}

1. Virginia G. Piper Cancer Center Clinical Trials at Scottsdale Healthcare, Scottsdale, AZ, USA

2. The Translational Genomics Research Institute (TGen), Phoenix, AZ, USA

Corresponding author: Glen J. Weiss, MD, 10510 N. 92nd St., Ste 200, Scottsdale, AZ 85238. E-mail:gweiss@tgen.org; Phone: (480) 323-1350; Fax: (480) 323-1359

( ) Ivyspring International Publisher. This is an open-access article distributed under the terms of the Creative Commons License (http://creativecommons.org/ licenses/by-nc-nd/3.0/). Reproduction is permitted for personal, noncommercial use, provided that the article is in whole, unmodified, and properly cited.

Received: 2011.07.22; Accepted: 2011.11.24; Published: 2011.11.28

\begin{abstract}
Background: There is often a finite progression-free interval of time between one systemic therapy and the next when treating patients with advanced cancer. While it appears that progression-free survival (PFS) between systemic therapies tends to get shorter for a number of factors, there has not been a formal evaluation of diverse tumor types in an advanced cancer population treated with commercially-available systemic therapies.

Methods: In an attempt to clarify the relationship between PFS between subsequent systemic therapies, we analyzed the records of 165 advanced cancer patients coming to our clinic for consideration for participation in six different phase I clinical trials requiring detailed and extensive past medical treatment history documentation.

Results: There were 77 men and 65 women meeting inclusion criteria with a median age at diagnosis of 55.3 years (range 9.4-8I.6). The most common cancer types were colorectal (I3.9\%), other gastrointestinal (I I.8\%), prostate (I I.8\%). A median of 3 (range I-I I) systemic therapies were received prior to phase I evaluation. There was a significant decrease in PFS in systemic therapy for advanced disease from treatment I to treatment 2 to treatment 3 ( $p=$ $0.002)$, as well as, from treatment I through treatment $5(p<0.00 I)$.

Conclusions: In an advanced cancer population of diverse tumor types, we observe a statistically significant decrease in PFS with each successive standard therapy. Identification of new therapies that reverse this trend of decreasing PFS may lead to improved clinical outcomes.
\end{abstract}

Key words: Progression-free survival, chemotherapy, advanced cancer, systemic therapy, phase I clinical trials

\section{Introduction}

The treatment of advanced/metastatic cancer often involves systemic chemotherapy. The most robust responses and lengthiest interval of time before disease progression is usually observed with first-line therapy ${ }^{1,2,3}$. Often, when progression occurs on first-line therapy, subsequent systemic therapies are offered in patients who are eligible for additional therapy based on clinical attributes such as performance status and acceptable laboratory parameters. Subsequent therapies are selected based on tumor type and treatment guidelines, availability of approved agents or off-label use of approved agents, or when feasible, eligibility to participate in a clinical trial involving systemic therapy of an investigational 
agent. It has been noted that the interval of time between subsequent therapies in advanced/metastatic cancer is reduced after each treatment. For example, progression-free survival (PFS) shortens such that Treatment $\mathrm{A}>$ Treatment $\mathrm{B}>$ Treatment $\mathrm{C}>$ Treatment $\mathrm{D}$, and so on ${ }^{1,2,3}$. Examination of the relationship between PFS and its impact on disease progression in advanced/metastatic cancer patients leading up to evaluation for participation in a phase I clinical trial has been limited.

Clinical factors that may affect the length of survival during phase I clinical trials for patients with advanced cancers have been identified. Patients receiving more than five prior treatments had a trend toward shorter survival ${ }^{4}$. A longer median PFS has been observed in lung cancer patients treated on phase I studies that had received two or less prior therapies compared to lung cancer patients treated with more than two prior therapies ${ }^{5}$. While it appears that PFS tends to get shorter for a number of factors (e.g. tumor progression, toxicity, or patient wishes), there has not been a formal evaluation in an advanced cancer population of diverse tumor types treated with commercially-available systemic therapies. We examined PFS between systemic therapies of commercially available agents prior to presenting for a phase I clinical trial evaluation at our institution.

\section{Materials and Methods}

Participants were all adults with a diagnosis of advanced/metastatic cancer at the time of signed informed consent for screening for a Phase I clinical trial at our center. All patients were selected for inclusion in this analysis because they consented for at least one of six of our phase I trials which require detailed past medical treatment histories, including prior treatment start and stop dates, past surgeries and radiotherapy treatment dates, as part of screening. Clinical characteristics collected include: subject diagnosis, histology, age, gender, stage at diagnosis, prior chemotherapy, prior surgery and radiation therapy, and PFS on systemic therapy for advanced/metastatic cancer was calculated from start of the first systemic therapy regimen for advanced/metastatic cancer $\left(t x_{n}\right)$ to the start of the next subsequent systemic therapy $\left(t_{n+1}\right)$, then $t x_{n+1}$ and $t x_{n+2}$, and so on. PFS between consecutive systemic therapies were calculated using the Jonckheere-Terpstra test. NOTE: if there was a palliative surgical or radiation intervention between one type of systemic therapy (e.g. $t x_{n+2}$ and $t x_{n+3}$ ), then additional PFS calculations were resumed from the starting point $t x_{n+3}$ to the start of $t x_{n+4}$, such that PFS was not calculated between start of $t x_{n+2}$ and $t x_{n+3}$.
Each patient's medical history was reviewed from the time of cancer diagnosis to presentation at our institution for clinical trial evaluation to determine the PFS for each line of therapy. Surgery, radiotherapy, herbal supplements, and investigational therapies were censored. Standard therapies given to patients subsequent to investigational therapies were censored from the data set. Progression dates were defined by the start date of the next chemotherapy agent given. When the exact day of the month for start or stop of a therapy was not provided, the $15^{\text {th }}$ of the month was assigned. When start and progression dates lacked information about the specific month or year, the treatment information was censored.

\section{Results}

\section{Patient Characteristics}

We reviewed the patient records of 165 unique patients that were evaluated for participation in six phase I trials. Due to a lack of specific start/stop dates, 25 patients had at least one treatment censored for analysis; with one of these patients not having PFS that could be calculated for this study. Seventeen of these twenty-five patients were diagnosed as having less than stage IV disease, with the majority of censored treatments (radiation, surgery, or neoadjuvant or adjuvant chemotherapy) occurring in the non-advanced/metastatic setting. One hundred forty-four patients met criteria for receiving at least one prior non-investigational systemic therapy for advanced/metastatic cancer prior to coming for a phase I treatment evaluation. There were 77 men and 65 women; median age at cancer diagnosis was 55.3 years (range, $9.4-81.6$ years). The most common types were: colorectal cancer $(n=20(13.9 \%))$, other gastrointestinal cancer $(\mathrm{n}=17(11.8 \%))$, adenocarcinoma of the prostate $(\mathrm{n}=17(11.8 \%))$, non-small cell lung cancer (NSCLC) $(\mathrm{n}=13(9.0 \%))$, breast cancer $(n=12(8.3 \%))$, ovarian cancer $(n=11(7.6 \%))$, and adenocarcinoma of the pancreas $(n=9(6.3 \%))$ (Table I). Patients had a median of three chemotherapy or hormonal treatments (mean, 3.32 treatments; range, 1 -11 treatments).

Two of the 144 patients did not receive a second systemic therapy prior to evaluation at our center, so PFS could be calculated for the remaining 142 patients. The PFS from $t x_{n}$ to $t x_{n+3}$ was significantly decreased ( $p=0.001850$ ) (Figure 1). Few advanced cancers have more than four lines of FDA-approved or consensus guidelines recommendations for systemic therapy, thus we examined the time to progression of the first five treatments $(\mathrm{p}=2.938 \mathrm{e}-07)$ (Figure 2). 
Table I. Patient Diagnoses, Gender, Median Age at Diagnosis and Median Number of Therapies

\begin{tabular}{llllll}
\hline & $\begin{array}{l}\text { Number of Pa- } \\
\text { tients* }\end{array}$ & Male & Female & $\begin{array}{l}\text { Median Age at Diagnosis } \\
\text { (range) (in years) }\end{array}$ & $\begin{array}{l}\text { Median Therapies } \\
\text { (range) (in years) }\end{array}$ \\
\hline Total & 142 & 77 & 65 & $55.7(9.4-81.6)$ & $3(1-11)$ \\
Colorectal & 20 & 11 & 9 & $55.3(33.1-79.9)$ & $4(2-9)$ \\
Other Gastrointestinal & 17 & 12 & 5 & $54.0(9.4-72.9)$ & $2(1-10)$ \\
Prostate & 17 & 17 & 0 & $60.3(52.0-75.2)$ & $3(2-8)$ \\
Breast & 12 & 1 & 11 & $44.9(28.0-57.3)$ & $7(3-11)$ \\
Non-small-cell Lung & 13 & 9 & 4 & $63.9(41.6-81.6)$ & $3(1-4)$ \\
Ovarian & 11 & 0 & 11 & $59.8(44.2-75.3)$ & $4(2-9)$ \\
Pancreatic & 9 & 6 & 3 & $61.0(31.7-79.6)$ & $1(1-4)$ \\
Gynecological & 8 & 0 & 8 & $39.6(24.4-69.7)$ & $1.5(1-3)$ \\
Head and Neck & 8 & 6 & 2 & $51.9(45.3-72.3)$ & $2(1-8)$ \\
Skin & 7 & 6 & 1 & $48.2(32.0-73.3)$ & $2(1-3)$ \\
Other & 6 & 1 & 5 & $52.4(39.5-62.7)$ & $2(1-5)$ \\
Small-cell Lung & 4 & 0 & 4 & $55.9(50.0-66.2)$ & $2.5(2-3)$ \\
Genitourinary & 3 & 3 & 0 & $53.2(19.5-66.6)$ & $3(2-4)$ \\
Sarcoma & 3 & 2 & 1 & $66.7(29.9-78.0)$ & $2(1-3)$ \\
Thoracic & 3 & 2 & 1 & $37.9(19.6-60.1)$ & $1(1-4)$ \\
Adrenal & 1 & 1 & 0 & $54.0(54.0-54.0)$ & $1(1-1)$ \\
\hline
\end{tabular}

"Other" include: unknown primary $(n=2)$, carcinoma $(n=1)$, eccrine sweat gland $(n=1)$, leiomyosarcoma $(n=1)$, occular melanoma $(n=1)$.

${ }^{*}$ Does not include patients that were censored from analysis.

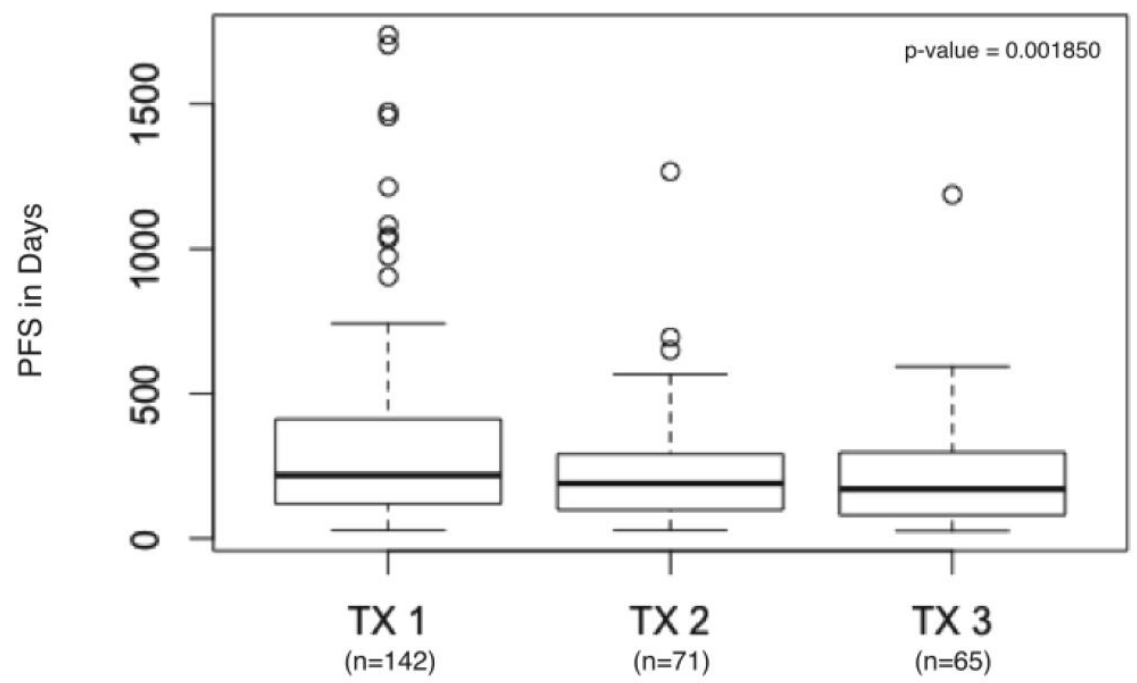

Systemic Therapy

Figure I. PFS in days from first systemic therapy to third systemic therapy. Boxplot detail showing significant decrease in PFS calculated for first systemic therapy (TXI), second systemic therapy (TX2), and third systemic therapy (TX3) in days. 


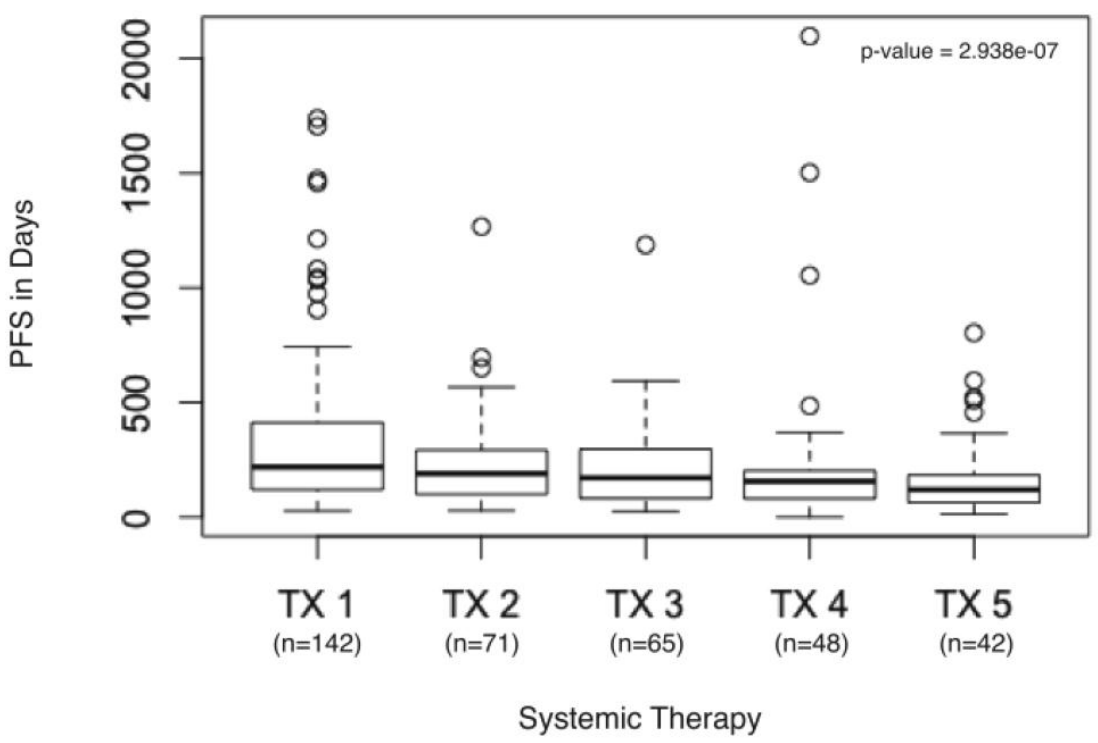

Figure 2. PFS in days from first systemic therapy to fifth systemic therapy. Boxplot detail showing significant decrease in PFS calculated for first systemic therapy (TXI), second systemic therapy (TX2), third systemic therapy (TX3), fourth systemic therapy (TX4), and fifth systemic therapy (TX5) in days.

\section{Discussion}

Statistical analyses revealed that there was a significant downward trend in PFS for patients on three standard therapies $(\mathrm{p}=0.001850)$ (Figure 1$)$. Most patients with advanced cancers have no more than four lines of approved treatment, we also examined the PFS of the first five treatments, again finding a significant downward trend $(\mathrm{p}=2.938 \mathrm{e}-07)$ (Figure 2).

Other reports support these findings of decreased PFS with subsequent therapies. In colorectal cancer, the median PFS is 6-10.6 months ${ }^{6-15}$, 2.3-7.3 months ${ }^{16-20}$, and 5.3-5.4 months ${ }^{21,22}$ for first-, second-, and third-line systemic therapies; respectively. In NSCLC, the median PFS is 4.2-13.1 months ${ }^{23-33}$ and 1.7-4.6 months ${ }^{34-43}$ for first- and second line-treatment; respectively. In gastro-esophageal cancer, the median PFS is 3.9-7.0 months ${ }^{44-49}$ and 1.8-4.1 months ${ }^{50-52}$ for first- and second-line therapy; respectively. The least favorable results are in patients with advanced pancreatic cancer, where the median PFS is 3.3-6.4 months ${ }^{53,54}$ and 1.4-4.1 months ${ }^{55-59}$ for first- and second-line treatment; respectively (Table II).

A reversal of decreasing PFS with therapy may suggest a change in the expected course of the disease. Recent examples of new therapies that have dramatically changed the disease course for patients with advanced cancer include targeted cancer therapies such as imatinib for chronic myelogenous leukemia and gastrointestinal stromal tumors (GIST) and erlotinib for NSCLC. In GIST patients treated with imatinib, a specific exon mutation in the tumor correlates with a higher response rate, PFS, and overall survival (OS) ${ }^{60-62}$. In NSCLC, it is the activating tyrosine kinase mutation in the tumor's EGFR gene that dramatically sensitizes this cancer to erlotinib and gefitinib ${ }^{63-67}$. These mutations had first been observed in clinical subgroups of NSCLC patients, primarily, Asian never-smoker women with adenocarcinoma ${ }^{60,68-71}$. Potential "therapeutic efficacy" subgroups may be recognized when a reversal in the expected decreasing PFS during therapy is observed.

Table II. Progression-free Survival for Successive Treatments in Supporting Articles. KEY: TX I - PFS for first-line systemic therapy, TX 2- PFS for second-line systemic therapy, TX 3- PFS for third-line systemic therapy.

\begin{tabular}{llll}
\hline Cancer Type & $\begin{array}{l}\text { TX1 } \\
\text { (months) }\end{array}$ & $\begin{array}{l}\text { TX2 } \\
\text { (months) }\end{array}$ & $\begin{array}{l}\text { TX3 } \\
\text { (months) }\end{array}$ \\
\hline Colorectal & $6-10.7$ & $2.3-7.3$ & $5.3-5.4$ \\
Non-small cell Lung & $4.2-13.1$ & $1.7-4.6$ & - \\
Gastro-esophageal & $3.9-7.0$ & $1.8-4.1$ & - \\
Pancreatic & $3.3-6.4$ & $1.4-4.1$ & - \\
\hline
\end{tabular}

\section{Acknowledgments}

We thank the patients and their families, and the rest of the medical team for their assistance.

\section{Conflict of Interest}

There are no financial disclosures from any authors. 


\section{References}

1. Armstrong DK. Relapsed ovarian cancer: challenges and management strategies for a chronic disease. Oncologist 2002;7:20-28.

2. Moroney J, Wheler J, Hong D, et al. Phase I clinical trials in 85 patients with gynecologic cancer: the M. D. Anderson Cancer Center experience. Gynecol Oncol. 2010;117:467-472.

3. Kiely BE, Soon YY, Tattersall MH, et al. How long have I got? Estimating typical, best-case, and worst-case scenarios for patients starting first-line chemotherapy for metastatic breast cancer: a systematic review of recent randomized trials. J Clin Oncol. 2011;29:456-463.

4. Wheler J, Tsimberidou AM, Hong D, et al. Survival of patients in a Phase 1 Clinic: the M. D. Anderson Cancer Center experience. Cancer. 2009;115:1091-1099.

5. Janku F, Tsimberidou AM, Wang X, et al. Outcomes of patients with advanced non-small cell lung cancer treated in a phase I clinic. Oncologist. 2011;16:327-335.

6. Hurwitz H, Fehrenbacher L, Novotny W, et al. Bevacizumab plus irinotecan, fluorouracil, and leucovorin for metastatic colorectal cancer. N Engl J Med. 2004;350:2335-2342.

7. Hurwitz HI, Fehrenbacher L, Hainsworth JD, et al. Bevacizumab in combination with fluorouracil and leucovorin: an active regimen for first-line metastatic colorectal cancer. J Clin Oncol. 2005;23:3502-3208.

8. Tebbutt NC, Wilson K, Gebski VJ, et al. Capecitabine, bevacizumab, and mitomycin in first-line treatment of metastatic colorectal cancer: results of the Australasian Gastrointestinal Trials Group Randomized Phase III MAX Study. J Clin Oncol. 2010;28:3191-3198.

9. Tol J, Koopman M, Cats A, et al. Chemotherapy, bevacizumab, and cetuximab in metastatic colorectal cancer. N Engl J Med. 2009;360:563-572.

10. Saltz LB, Clarke S, Díaz-Rubio E, et al. Bevacizumab in combination with oxaliplatin-based chemotherapy as first-line therapy in metastatic colorectal cancer: a randomized phase III study. J Clin Oncol. 2008;26:2013-9.

11. Guan ZZ, Xu JM, Luo RC, et al. Efficacy and safety of bevacizumab plus chemotherapy in Chinese patients with metastatic colorectal cancer: a randomized phase III ARTIST trial. Chin J Cancer. 2011;30:682-689.

12. Fischer von Weikersthal L, Schalhorn A, Stauch M, et al. Phase III trial of irinotecan plus infusional 5-fluorouracil/folinic acid versus irinotecan plus oxaliplatin as first-line treatment of advanced colorectal cancer. Eur J Cancer. 2011;47:206-214.

13. Blanke CD, Bot BM, Thomas DM, et al. Impact of young age on treatment efficacy and safety in advanced colorectal cancer: a pooled analysis of patients from nine first-line phase III chemotherapy trials. J Clin Oncol. 2011;29:2781-2786.

14. Hecht JR, Trarbach T, Hainsworth JD, et al. Randomized, placebo-controlled, phase III study of first-line oxaliplatin-based chemotherapy plus PTK787/ZK 222584, an oral vascular endothelial growth factor receptor inhibitor, in patients with metastatic colorectal adenocarcinoma. J Clin Oncol. 2011;29:1997-2003.

15. Douillard JY, Siena S, Cassidy J, et al. Randomized, phase III trial of panitumumab with infusional fluorouracil, leucovorin, and oxaliplatin (FOLFOX4) versus FOLFOX4 alone as first-line treatment in patients with previously untreated metastatic colorectal cancer: the PRIME study. J Clin Oncol. 2010;28:4697-4705.

16. Peeters M, Price TJ, Cervantes A, et al. Randomized phase III study of panitumumab with fluorouracil, leucovorin, and irinotecan (FOLFIRI) compared with FOLFIRI alone as second-line treatment in patients with metastatic colorectal cancer. J Clin Oncol. 2010;28:4706-4713.
17. Muro K, Boku N, Shimada Y, et al. Irinotecan plus S-1 (IRIS) versus fluorouracil and folinic acid plus irinotecan (FOLFIRI) as second-line chemotherapy for metastatic colorectal cancer: a randomised phase $2 / 3$ non-inferiority study (FIRIS study). Lancet Oncol. 2010;11:853-860.

18. Bidard FC, Tournigand C, André T, et al. Efficacy of FOLFIRI-3 (irinotecan D1,D3 combined with LV5-FU) or other irinotecan-based regimens in oxaliplatin-pretreated metastatic colorectal cancer in the GERCOR OPTIMOX1 study. Ann Oncol. 2009;20:1042-1047.

19. Sobrero AF, Maurel J, Fehrenbacher L, et al. EPIC: phase III trial of cetuximab plus irinotecan after fluoropyrimidine and oxaliplatin failure in patients with metastatic colorectal cancer. J Clin Oncol. 2008;26:2311-2319.

20. Van Cutsem E, Bajetta E, Valle J, et al. Randomized, placebo-controlled, phase III study of oxaliplatin, fluorouracil, and leucovorin with or without PTK787/ZK 222584 in patients with previously treated metastatic colorectal adenocarcinoma. J Clin Oncol. 2011;29:2004-2010.

21. Pfeiffer P, Nielsen D, Bjerregaard J, Qvortrup C, Yilmaz M, Jensen B. Biweekly cetuximab and irinotecan as third-line therapy in patients with advanced colorectal cancer after failure to irinotecan, oxaliplatin and 5-fluorouracil. Ann Oncol. 2008;19:1141-1145.

22. Kang BW, Kim TW, Lee JL, et al. Bevacizumab plus FOLFIRI or FOLFOX as third-line or later treatment in patients with metastatic colorectal cancer after failure of 5-fluorouracil, irinotecan, and oxaliplatin: a retrospective analysis. Med Oncol. 2009;26:32-37.

23. Gridelli C, De Marinis F, Di Maio M, Cortinovis D, Cappuzzo F, Mok T. Gefitinib as first-line treatment for patients with advanced non-small-cell lung cancer with activating epidermal growth factor receptor mutation: Review of the evidence. Lung Cancer. 2011;71:249-257

24. Mok TS, Wu YL, Thongprasert S, et al. Gefitinib or carboplatin-paclitaxel in pulmonary adenocarcinoma. N Engl J Med. 2009;361:947-957.

25. Lee JS, Park K, Kim SW, et al. A randomized phase III study of gefitinib (IRESSA) versus standard chemotherapy (gemcitabine plus cisplatin) as a first-line treatment for never-smokers with advanced or metastatic adenocarcinoma of the lung. Proceedings World Conference Lung Cancer. 2009;:AbsPRS4.

26. Mitsudomi T, Morita S, Yatabe Y, et al. Gefitinib versus cisplatin plus docetaxel in patients with non-small-cell lung cancer harbouring mutations of the epidermal growth factor receptor (WJTOG3405): an open label, randomised phase 3 trial. Lancet Oncol. 2010;11:121-128.

27. Maemondo $M$, Inoue $A$, Kobayashi $K$, et al. Gefitinib or chemotherapy for non-small-cell lung cancer with mutated EGFR. N Engl J Med. 2010;362:2380-2388.

28. Lara PN Jr, Douillard JY, Nakagawa K, et al. Randomized phase III placebo-controlled trial of carboplatin and paclitaxel with or without the vascular disrupting agent vadimezan (ASA404) in advanced non-small-cell lung cancer. J Clin Oncol. 2011;29:2965-2971.

29. Hirsh V, Paz-Ares L, Boyer M, et al. Randomized phase III trial of paclitaxel/carboplatin with or without PF-3512676 (Toll-like receptor 9 agonist) as first-line treatment for advanced non-small-cell lung cancer. J Clin Oncol. 2011;29:2667-2674.

30. Weissman $\mathrm{CH}$, Reynolds $\mathrm{CH}$, Neubauer MA, et al. A phase III randomized trial of gemcitabine-oxaliplatin versus carboplatin-paclitaxel as first-line therapy in patients with advanced non-small cell lung cancer. J Thorac Oncol. 2011;6:358-364.

31. Reck M, von Pawel J, Zatloukal P, et al. Overall survival with cisplatin-gemcitabine and bevacizumab or placebo as first-line therapy for nonsquamous non-small-cell lung cancer: results 
from a randomised phase III trial (AVAiL). Ann Oncol. 2010;21:1804-1809.

32. Lynch TJ, Patel T, Dreisbach L, et al. Cetuximab and first-line taxane/carboplatin chemotherapy in advanced non-small-cell lung cancer: results of the randomized multicenter phase III trial BMS099. J Clin Oncol. 2010;28:911-917.

33. Zhou C, Wu YL, Chen G, et al. Erlotinib versus chemotherapy as first-line treatment for patients with advanced EGFR mutation-positive non-small-cell lung cancer (OPTIMAL, CTONG-0802): a multicentre, open-label, randomised, phase 3 study. Lancet Oncol. 2011;12:735-742.

34. Fidias PM, Dakhil SR, Lyss AP, et al. Phase III study of immediate compared with delayed docetaxel after front-line therapy with gemcitabine plus carboplatin in advanced non-small-cell lung cancer. J Clin Oncol. 2009;27:591-598.

35. Herbst RS, Sun Y, Eberhardt WE, et al. Vandetanib plus docetaxel versus docetaxel as second-line treatment for patients with advanced non-small-cell lung cancer (ZODIAC): a double-blind, randomised, phase 3 trial. Lancet Oncol. 2010;11:619-626.

36. Krzakowski M, Ramlau R, Jassem J, et al. Phase III trial comparing vinflunine with docetaxel in second-line advanced non-small-cell lung cancer previously treated with platinum-containing chemotherapy. J Clin Oncol. 2010;28:2167-2173.

37. de Boer $\mathrm{RH}$, Arrieta Ó, Yang $\mathrm{CH}$, et al. Vandetanib plus pemetrexed for the second-line treatment of advanced non-small-cell lung cancer: a randomized, double-blind phase III trial. J Clin Oncol. 2011;29:1067-1074.

38. Pallis AG, Agelaki S, Agelidou A, et al. A randomized phase III study of the docetaxel/carboplatin combination versus docetaxel single-agent as second line treatment for patients with advanced/metastatic non-small cell lung cancer. BMC Cancer. 2010;10:633.

39. Lee DH, Park K, Kim JH, et al. Randomized Phase III trial of gefitinib versus docetaxel in non-small cell lung cancer patients who have previously received platinum-based chemotherapy. Clin Cancer Res. 2010;16:1307-1314.

40. Cullen MH, Zatloukal P, Sörenson S, et al. A randomized phase III trial comparing standard and high-dose pemetrexed as second-line treatment in patients with locally advanced or metastatic non-small-cell lung cancer. Ann Oncol. 2008;19:939-945.

41. Shepherd FA, Rodrigues Pereira J, et al. Erlotinib in previously treated non-small-cell lung cancer. $\mathrm{N}$ Engl J Med. 2005;353:123-132.

42. Herbst RS, Ansari R, Bustin F, et al. Efficacy of bevacizumab plus erlotinib versus erlotinib alone in advanced non-small-cell lung cancer after failure of standard first-line chemotherapy (BeTa): a double-blind, placebo-controlled, phase 3 trial. Lancet. 2011;377:1846-1854.

43. Hanna N, Shepherd FA, Fossella FV, et al. Randomized phase III trial of pemetrexed versus docetaxel in patients with non-small-cell lung cancer previously treated with chemotherapy. J Clin Oncol. 2004;22:1589-1597.

44. Cunningham D, Starling N, Rao S, et al. Capecitabine and oxaliplatin for advanced esophagogastric cancer. N Engl J Med. 2008;358:36-46.

45. Van Cutsem E, Moiseyenko VM, Tjulandin S, et al. Phase III study of docetaxel and cisplatin plus fluorouracil compared with cisplatin and fluorouracil as first-line therapy for advanced gastric cancer: a report of the V325 study group. J Clin Oncol. 2006;24:4991-4997.

46. Ajani JA, Rodriguez W, Bodoky G, et al. Multicenter phase III comparison of cisplatin/S-1 with cisplatin/infusional fluorouracil in advanced gastric or gastroesophageal adenocarcinoma study: the FLAGS trial. J Clin Oncol. 2010;28:1547-1553.
47. Koizumi W, Narahara H, Hara T, et al. S-1 plus cisplatin versus S-1 alone for first-line treatment of advanced gastric cancer (SPIRITS trial): a phase III trial. Lancet Oncol. 2008;9:215-221.

48. Ohtsu A, Shah MA, Van Cutsem E, et al. Bevacizumab in Combination With Chemotherapy As First-Line Therapy in Advanced Gastric Cancer: A Randomized, Double-Blind, Placebo-Controlled Phase III Study. J Clin Oncol. 2011;[Epub ahead of print]

49. Al-Batran SE, Hartmann JT, Probst S, et al. Phase III trial in metastatic gastroesophageal adenocarcinoma with fluorouracil, leucovorin plus either oxaliplatin or cisplatin: a study of the Arbeitsgemeinschaft Internistische Onkologie. J Clin Oncol. 2008;26:1435-1442.

50. Schoennemann KR, Bjerregaard JK, Hansen TP, et al. Biweekly cetuximab and irinotecan as second-line therapy in patients with gastro-esophageal cancer previously treated with platinum. Gastric Cancer. 2011 Aug;14(3):219-25.

51. Hamaguchi T, Shirao K, Ohtsu A, et al. A phase II study of biweekly mitomycin $\mathrm{C}$ and irinotecan combination therapy in patients with fluoropyrimidine-resistant advanced gastric cancer: a report from the Gastrointestinal Oncology Group of the Japan Clinical Oncology Group (JCOG0109-DI Trial). Gastric Cancer. 2011;14:226-233.

52. Gold PJ, Goldman B, Iqbal S, et al. Cetuximab as second-line therapy in patients with metastatic esophageal adenocarcinoma: a phase II Southwest Oncology Group Study (S0415). J Thorac Oncol. 2010;5:1472-1476.

53. Arshad A, Al-Leswas D, Al-Taan O, et al. Pooled Survival and Response Data From Phase III Randomized Controlled Trials for Gemcitabine-based Regimes in the Treatment of Advanced Pancreatic Cancer. Am J Clin Oncol. 2011; [Epub ahead of print].

54. Conroy T, Desseigne F, Ychou M, et al. FOLFIRINOX versus gemcitabine for metastatic pancreatic cancer. $\mathrm{N}$ Engl J Med. 2011;364:1817-1825.

55. Xiong HQ, Varadhachary GR, Blais JC, et al. Phase 2 trial of oxaliplatin plus capecitabine (XELOX) as second-line therapy for patients with advanced pancreatic cancer. Cancer. 2008; 113:2046-2052.

56. Katopodis O, Polyzos A, Kentepozidis N, et al. Second-line chemotherapy with capecitabine (Xeloda) and docetaxel (Taxotere) in previously treated, unresectable adenocarcinoma of pancreas: the final results of a phase II trial. Cancer Chemother Pharmacol. 2011;67:361-368.

57. Sudo K, Yamaguchi T, Nakamura K, et al. Phase II study of S-1 in patients with gemcitabine-resistant advanced pancreatic cancer. Cancer Chemother Pharmacol. 2011;67:249-254.

58. Todaka A, Fukutomi A, Boku N, et al. S-1 monotherapy as second-line treatment for advanced pancreatic cancer after gemcitabine failure. Jpn J Clin Oncol. 2010;40:567-572.

59. Astsaturov IA, Meropol NJ, Alpaugh RK, et al. Phase II and coagulation cascade biomarker study of bevacizumab with or without docetaxel in patients with previously treated metastatic pancreatic adenocarcinoma. Am J Clin Oncol. 2011;34:70-75.

60. Blay JY, Le Cesne A, Alberti L, Ray-Coquart I. Targeted cancer therapies. Bull Cancer. 2005;92:E13-18.

61. Heinrich MC, Corless CL, Demetri GD, et al. Kinase mutations and imatinib response in patients with metastatic gastrointestinal stromal tumor. J Clin Oncol. 2003;21:4342-4349.

62. Debiec-Rychter M, Dumez H, Judson I, et al. Use of c-KIT/PDGFRA mutational analysis to predict the clinical response to imatinib in patients with advanced gastrointestinal stromal tumours entered on phase I and II studies of the EORTC Soft Tissue and Bone Sarcoma Group. Eur J Cancer. 2004:40:689-95.

63. Sridhar SS, Seymour L, Shepherd FA. Inhibitors of epidermal-growthfactor receptors: a review of clinical research with a 
focus on non-small-cell lung cancer. Lancet Oncol. 2003;4:397-406.

64. Giaccone G. The role of gefitinib in lung cancer treatment. Clin Cancer Res. 2004;10:4233s-4237s.

65. Birnbaum A, Ready N. Gefitinib therapy for non-small cell lung cancer. Curr Treat Options Oncol. 2005;6:75-81.

66. Perez-Soler R, Chachoua A, Hammond LA, et al. Determinants of tumor response and survival with erlotinib in patients with non--small-cell lung cancer. J Clin Oncol. 2004;22:3238.

67. Cappuzzo F, Gregorc V, Rossi E, et al. Gefitinib in pretreated non-smallcell lung cancer (NSCLC) : analysis of efficacy and correlation with HER2 and epidermal growth factor receptor expression in locally advanced or metastatic NSCLC. J Clin Oncol. 2003;21:2658-2663.

68. Lynch TJ, Bell DW, Sordella R, et al. Activating mutations in the epidermal growth factor receptor underlying responsiveness of non-small-cell lung cancer to gefitinib. $N$ Engl J Med. 2004;350:2129-2139.

69. Paez JG, Janne PA, Lee JC, et al. EGFR mutations in lung cancer: correlation with clinical response to gefitinib therapy. Science. 2004;304:1497-1500.

70. Sordella R, Bell DW, Haber DA, Settleman J. Gefitinib-sensitizing EGFR mutations in lung cancer activate anti-apoptotic pathways. Science. 2004;305:1163-1167.

71. Pao W, Miller V, Zakowski M, et al. EGF receptor gene mutations are common in lung cancers from " never smokers" and are associated with sensitivity of tumors to gefitinib and erlotinib. Proc Natl Acad Sci USA. 2004; 101:13306-13311.

72. Giantonio BJ, Catalano PJ, Meropol NJ, et al. Bevacizumab in combination with oxaliplatin, fluorouracil, and leucovorin (FOLFOX4) for previously treated metastatic colorectal cancer: results from the Eastern Cooperative Oncology Group Study E3200. J Clin Oncol. 2007;25:1539-1544. 